\title{
Simulation Study of the Thermal Performance of MSF Desalination Unit Operating by Solar Vacuum Tube Collectors
}

\author{
Mohammad .J.R. Abdunnabi ${ }^{1}$, and Abdulghani .M. Ramadan ${ }^{2}$ \\ ${ }^{1}$ Centre for Solar Energy Research and Studies, Tajoura, P.O. Box 12932 Tripoli-Libya \\ e-mail: Moh jum@yahoo.com
}

${ }^{2}$ Faculty of Engineering, Mechanical Engineering, Al-Mergeb University, Al-Khomes

e-mail: Abdulghanir@yahoo.com

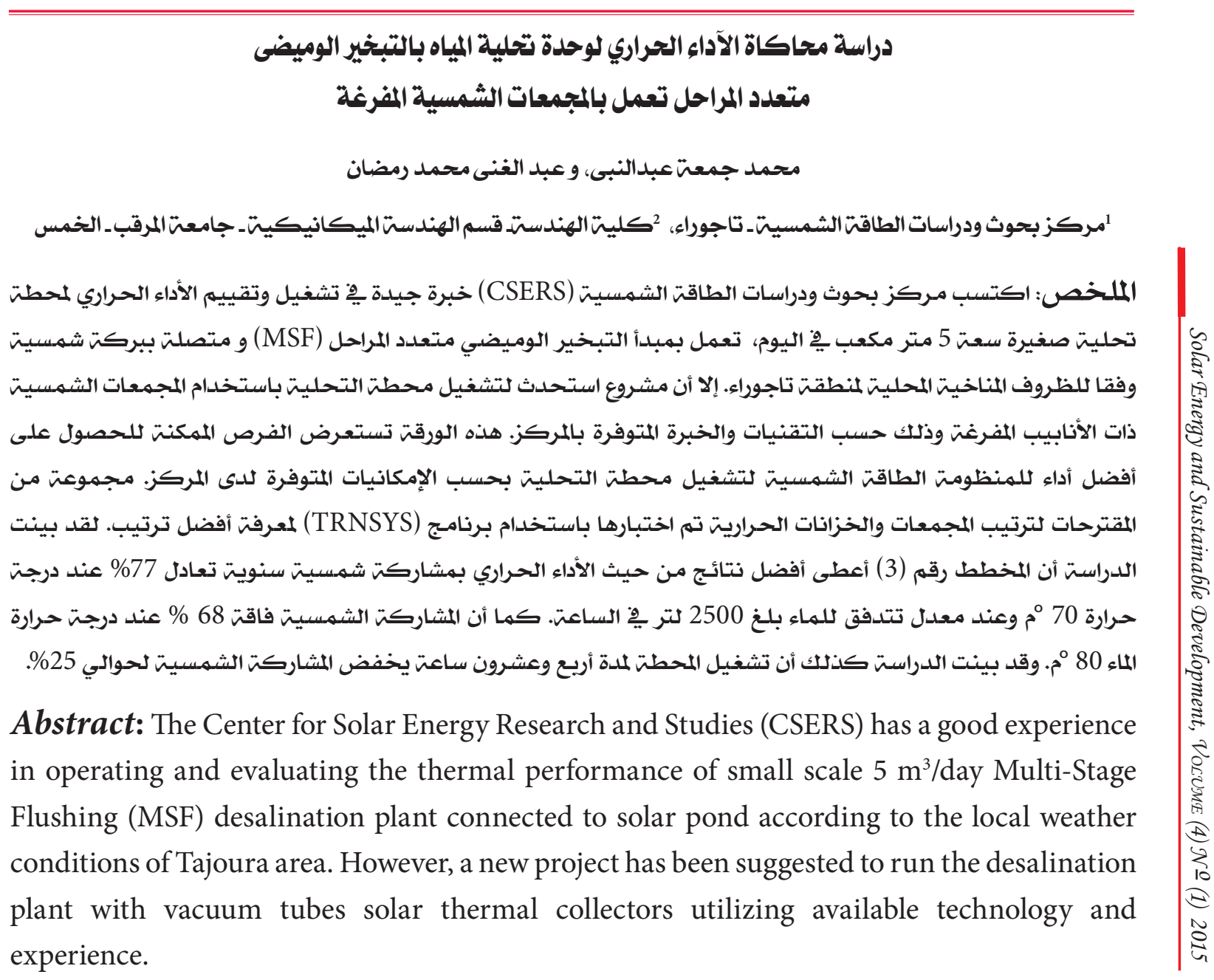

In this study an attempt was made to make the best use of readily available components to operate the MSF desalination unit with field of solar thermal collectors. Several configurations 
of collectors and tank arrangements were designed and examined through the use of simulation software, TRNSYS. The study has shown that the layout-3 (two 500 litre storage tanks each of them connected to $9 \mathrm{x} 5$ vacuum tube collectors) gives the best performance with an annual solar fraction over $77 \%$ at load temperature of $70{ }^{\circ} \mathrm{C}$ with flow rate of $2500 \mathrm{lit} / \mathrm{hr}$, and over $68 \%$ at load temperature of $80^{\circ} \mathrm{C}$ for working condition of 8 hours daily.

The study has also shown that running the desalination plant for 24 hours a day reduces the solar fraction of the solar collector field to $25 \%$

Keywords: MSF desalination plant, fresh water, configuration optimisation, simulation, TRNSYS

\section{INTRODUCTION}

All aspects of life and human activities on earth depend strongly on the availability of water. Water is the main source of life on our planet. About three-fourths of the earth's surface are covered by water. Unfortunately, about $97.5 \%$ of this water is salt water present in seas and oceans. Only, about $2.5 \%$ of it, is fresh water contained in underground and surface waters of which $80 \%$ is frozen in glaciers. The rest percentage of all fresh water is underground in deep and hard to reach aquifers. Only $0.5 \%$ of the total fresh water available is contained in the lakes and rivers [1].

Lack of fresh water is one of the main problems that affect many countries around the world. In arid areas, potable or fresh water is very scarce and the establishment of a human habitat in these areas strongly depends on how such water can be made available [2]. Water shortages involve more than 80 countries and $40 \%$ of the world population [3]. There are 1.1 billion people without adequate drinking water. Based on forecasts for 2020, it is expected that world population will reach 7.5 billions of which over $60 \%$ will be exposed to water shortages. This is due to the rapid increase of population, changes in the life-style, increased economic activities, and pollution that limits the use of fresh water resources. Moreover, common use of unhealthy water in developing countries causes $80-90 \%$ of all diseases and 30\% of all deaths. Even in industrial countries, long spells of dry seasons and limited rainfall force governments, states, and municipalities to adopt severe water restriction programs that affect the population at large. Such situations are reported on frequent basis in several countries around the globe [4].

Reports and studies about the future of water situation in the Arab region draw a gloomy picture. The water crisis is probably more serious than the energy crisis since alternatives to oil for energy production can always be found. Whereas there is no substitute for fresh water. In order to alleviate this problem, it is deemed necessary to resort to non-traditional sources of water, particularly water desalination technologies. The Arab world has long coasts on the seas and oceans, making it an appropriate source for fresh water. It is worth mentioning that 
more than $60 \%$ of the total capacity of the world's fresh water removed salinity is produced in the Arab region. The main desalination units used are multistage flushing, MSF and Reverse Osmosis, RO [5].

Libya has high solar insolation with an estimated daily average of solar radiation falling on the ground level about 8 kilowatt -hour per square meter during the month of June. This is the average of the highest solar radiation areas in the world. Moreover, 95\% purity of the skies or clear days each year is available, in addition to the favorable climate of air temperature and relative humidity. However, Libya lies in North Africa region where precipitation rates are very low and fresh water availability is a dilemma. Therefore, water desalination is the last resort to overcome the issue of fresh water shortage. Desalination plants in Libya are almost dependent on thermal technology. The total fresh water production of desalination plants in Libya in 2007 is over 46.5 million cubic meters [5]. Most of these plants are operated by the General Electrical Company of Libya (GECOL). A world-wide survey shows that Libya is the largest operator of desalination plants in North Africa and the Mediterranean basin and is ranked the sixth country in the world to use desalination as a resource of water for urban use [6].

The Center for Solar Energy Research and Studies (CSERS) has conducted extensive research work in the field of water desalination through the use of the solar pond. Since 2001, the Center has installed a multi-stage flushing (MSF) desalination plant using low grade heat energy that is collected in the pond as a source of energy for this system. The aim of this project is to identify the possibilities and advantages of solar ponds under local conditions and their suitability for the techniques of MSF desalination units. Thermal energy at relatively low temperatures makes it suitable for blending with several solar thermal systems. Solar ponds come in the forefront of these systems as they have the ability to provide thermal energy at a temperature ranging between 60 and 80 degrees Celsius throughout the year. To ensure the work of the desalination unit well, it has been designed to suit the heat source of the solar pond. Average daily production of fresh water reaches 5 cubic meters per day ( 0.208 cubic meters per hour) under designed working temperature of $80^{\circ} \mathrm{C}[7,8]$.

\section{DESIGNING AND SIZING SOLAR THERMAL FIELD}

There are many ways used to determine the required area of solar collector's field to cover the specific load according to the collector specification, weather conditions, and operating conditions. These methods are categorized from simple to use to very complicated that require a lot of accurate information such as simulation tools.

In this study the design and layout of collector field is carried out through the use of TRNSYS simulation program, the detailed information required for the simulations are given below: 


\subsection{Weather conditions}

The project is located in Tajoura city $\left(32^{\circ}\right.$ $815^{\prime}, 13^{\circ} 438^{\prime}$ ) suburb to Tripoli capital of Libya. The TMY2 weather data provided by TRNSYS program are used in this study.

\subsection{Operating conditions}

Operating condition has great influence as weather condition on the performance of the system, thus it has to be considered in the designing stage. In this study, due to the insufficient collector area to run the MSF unit for 24 hours with high solar fraction, it is considered to run the MSF unit 8 hours daily from 9 am to $5 \mathrm{pm}$ with flow rate of 2500 litres per hour at temperature of $70{ }^{\circ} \mathrm{C}$ as shown in Figure 1.

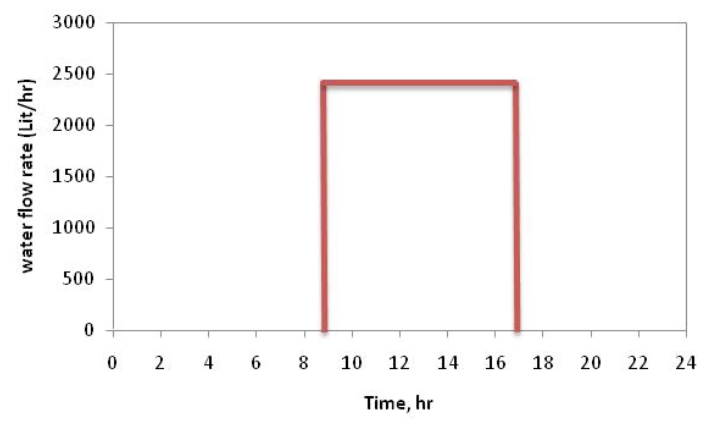

Figure (1). Hot water load pattern

\subsection{MSF desalination unit}

A 5 cubic meter per day Multi-Stage Flushing (MSF) desalination unit with 14 stages available at the Center will be used in this project. This plant was used previously in the solar pond project. The technical specifications for this plant are shown in Table 1. The plant is capable of working over a wide temperature range of low grade thermal energy input without loss of efficiency. The maximum designed working temperature is $80^{\circ} \mathrm{C}$, and the preferable range of operation is between $70-80{ }^{\circ} \mathrm{C}$.

Table (1). Technical specifications of the MSF plant.

\begin{tabular}{|l|l|}
\hline \multicolumn{1}{|c|}{ Item } & \multicolumn{1}{|c|}{ value } \\
\hline $\begin{array}{l}\text { Average daily production of } \\
\text { fresh water }\end{array}$ & $\begin{array}{l}5 \mathrm{~m}^{3} / \text { day }(0.208 \\
\left.\mathrm{m}^{3} / \mathrm{hr}\right)\end{array}$ \\
\hline Max working temperature & $80^{\circ} \mathrm{C}$ \\
\hline Sea water temperature & $20^{\circ} \mathrm{C}$ \\
\hline $\begin{array}{l}\text { Thermal energy consumption } \\
15.6 \mathrm{~kW}\end{array}$ \\
\hline $\begin{array}{l}\text { Designed specific consumption } \\
\text { of electric power }\end{array}$ & $\begin{array}{l}4.8 \mathrm{kilowatt} \\
\text { hour per cubic } \\
\mathrm{meter} .\end{array}$ \\
\hline $\begin{array}{l}\text { Rate of flow of sea water } \\
\text { (nutrition and cooling) }\end{array}$ & $2.3 \mathrm{~m}^{3} / \mathrm{hr}$ \\
\hline $\begin{array}{l}\text { Flow rate of saline solution } \\
\text { Concentration of the }\end{array}$ & $35,000 \mathrm{ppm}$. \\
\hline $\begin{array}{l}\text { Mediterranean sea waters } \\
\text { Specifications of desalinated } \\
\text { water }\end{array}$ & $<100 \mathrm{ppm}$ \\
\hline
\end{tabular}

\subsection{Solar collector field layout}

The solar collector field is mainly used to provide the MSF desalination unit with the required hot sea water at temperature ranging from 70 to $80{ }^{\circ} \mathrm{C}$, with a flow rate of 2500 litres per hour (taken from the experience of running MSF unit in the solar pond project). The number of collectors available to be utilized in this project is 92 evacuated tube solar collectors (AMK-DRC-10) with technical specifications given in Table 2. The total gross area of the collectors is over $187 \mathrm{~m}^{2}$. Four thermal storage tanks (two: 1000 litres and two: 500 litres) are available to be used to stabilize and store thermal energy during the operating time, as well as pump stations, safety and control equipments. These collectors would 
be arranged and connected optimally in rows and columns to get the best combination that gives the highest annual solar fraction.

Table (2). Collector technical and thermal specifications

\begin{tabular}{|l|c|}
\hline \multicolumn{1}{|c|}{ Parameter } & Value \\
\hline Length $(\mathrm{mm})$ & 2040 \\
\hline Width $(\mathrm{mm})$ & 1000 \\
\hline Depth $(\mathrm{mm})$ & 102 \\
\hline Gross area $\left(\mathrm{m}^{2}\right)$ & 2.04 \\
\hline Active area $\left(\mathrm{m}^{2}\right)$ & 2.73 \\
\hline Aperture area $\left(\mathrm{m}^{2}\right)$ & 1.74 \\
\hline Weight $(\mathrm{kg})$ & 50 \\
\hline$\eta_{\mathrm{o}}$ & 0.596 \\
\hline a1 $\left(\mathrm{W} / \mathrm{m}^{2} / \mathrm{K}\right)$ & 0.91 \\
\hline a2 $\left(\mathrm{W} / \mathrm{m}^{2} / \mathrm{k}^{2}\right)$ & 0.0034 \\
\hline
\end{tabular}

A number of configurations were examined in this study to find the optimum performance by using TRNSYS simulation program. Six of the best examined combinations are presented graphically as shown in annex A. The differences are mainly in the collector layout (number of rows and columns) and the total storage capacity of the tanks.

\section{SIMULATION PROGRAMS}

In this study, a very famous simulation software TRNSYS is used to design and evaluate the thermal performance of the solar thermal system. TRNSYS simulation program [9] is a very powerful tool for designing and evaluating the long term thermal performance of solar water heating systems and studying the effect of system design parameters, operating conditions, and weather conditions. The basicidea of TRNSYS is based on modeling each component in a system as module. The program in TRNSYS comprises many subroutines that model subsystem components. The subsystem components included in the standard library are programmed in the FORTRAN language. In addition to the standard library there is also TESS Library and non-standard components. In this study, evacuated tube collector component (Type 538), and storage tank component (Type 534) similar to the actual components are taken from TESS Library. Other components such as pumps, flow diverters, and utility components are also used. The desalination plant is not incorporated in TRNSYS, and therefore is simulated as heat exchanger.

\section{RESULTS AND DISCUSSION}

\subsection{Layout selection}

Six configurations were examined through the use of TRNSYS simulation, and the results of the average annual solar fraction are shown in Figure 2. The results showed that the layout- 3 gives the highest annual solar fraction and has been chosen in this study.

\subsection{Collector optimum tilt angle}

\subsubsection{Annual optimum tilt angle}

The annual collector optimum tilt angle was searched and was found equal to 35 degree for stationary collectors facing to the south. Figure 3 shows the annual system solar fraction at different tilt angles, and it was very clear optima at tilt angle equal to 35 degree with maximum annual solar fraction over $77 \%$. 


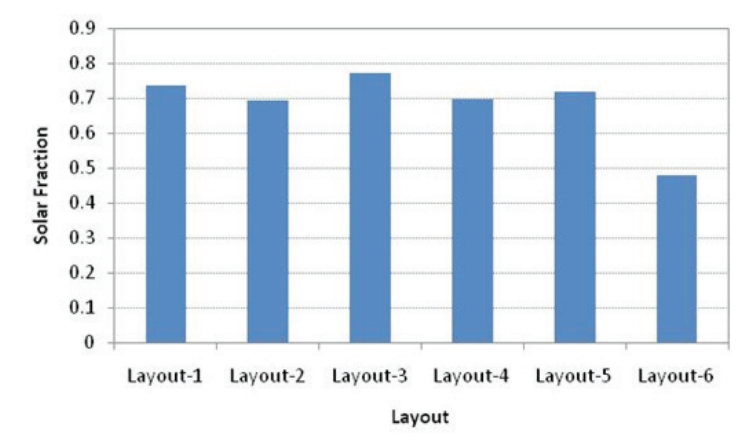

Figure (2). Thermal performance of the

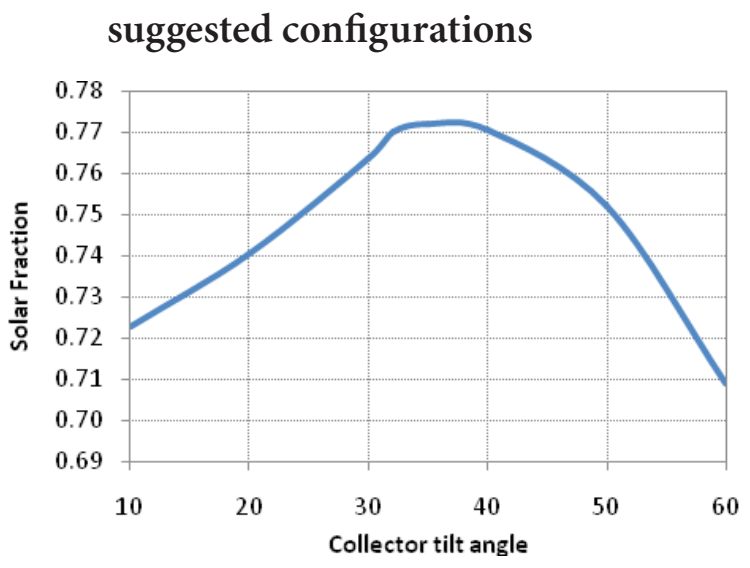

Figure (3). Effect of collector tilt angle on the annual system solar fraction

\subsubsection{Monthly and seasonally tilt angle}

Figure 4 shows the monthly average solar fraction of the system at monthly fixed value of optimum collector tilt angles, the annual system solar fraction is increased by $2 \%$ over annual optimum collector angle. The average annual solar fraction was found equal to $78.9 \%$. The monthly optimum tilt angles are shown in Table 3.

The fact that adjusting the tilt angle to its monthly optimum values throughout the year does not seem to be practical to give rise to the consideration of changing the tilt angle once seasonally. The fixed optimum tilt angles for each season are shown in Table 3. The optimum tilt angles which will be changed only four times during the year give slightly better performance than annual optimum tilt angle, and a slightly lower performance than monthly optimum tilt angle. The annual solar fraction of seasonally optimum tilt angles system was found to be $78.3 \%$.

Figures $5 a, 5 b$, and $5 c$ show the variation of outlet water temperature from the collector field at different tilt angles. It is very clear that collector tilt angle has great influence on the system performance and has to be selected properly or changed monthly to maximize the thermal energy output from the collector field.

Table (3). Monthly and seasonally optimum tilt angle

\begin{tabular}{|c|c|c|c|c|}
\hline \multirow{3}{*}{ Seasonally } & Spring & Summer & Autumn & Winter \\
\cline { 2 - 5 } & 35 & 10 & 50 & 60 \\
\hline \multirow{4}{*}{ Monthly } & Jan & Feb & Mar & Apr \\
\cline { 2 - 5 } & 60 & 35 & 30 & 32 \\
\cline { 2 - 5 } & May & Jun & Jul & Aug \\
\cline { 2 - 5 } & 32 & 40 & 10 & 10 \\
\cline { 2 - 5 } & Sep & Oct & Nov & Dec \\
\cline { 2 - 5 } & 40 & 32 & 50 & 60 \\
\hline
\end{tabular}

\subsection{Beam radiation}

The vacuum tube technology depends mainly on the beam radiation rather than the global radiation as in the case of Flat plate solar collectors. Figure 6 shows the distribution of the beam radiation over the year at different tilt angles. The annual average daily beam solar irradiance is $15.18 \mathrm{MJ} / \mathrm{m}^{2} /$ day. The maximum average daily beam irradiance was in April with $19.67 \mathrm{MJ} / \mathrm{m}^{2} /$ day and the minimum was in February with $10.53 \mathrm{MJ} / \mathrm{m}^{2} /$ day. The average annual value of beam radiation to global radiation was over $69 \%$. 


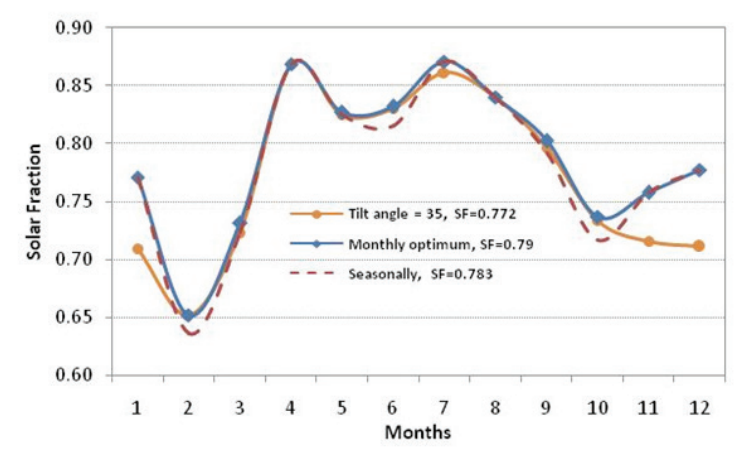

Figure (4). Seasonal and monthly optimum collector tilt angle

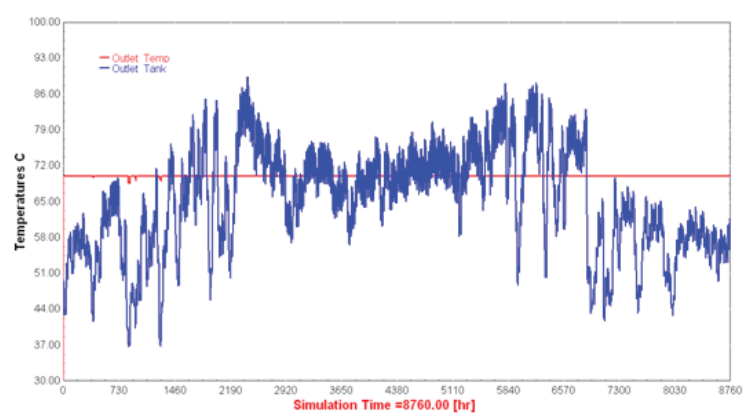

Figure (5 a). Collector tilt angle $=30$

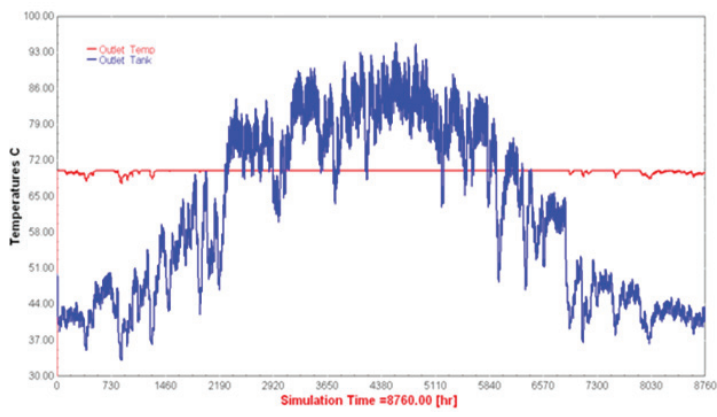

Figure ( 5 b). Collector tilt angle $=15$

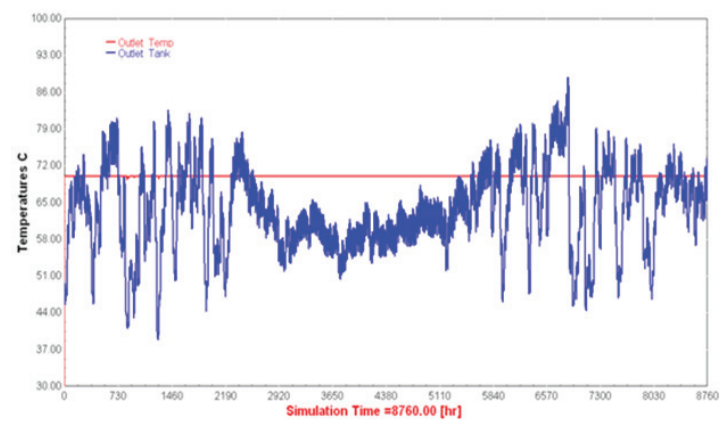

Figure (5 c). Collector tilt angle $=45$

\subsection{Water temperature}

The desired temperature to run the desalination plant selected in the simulation program is $70^{\circ} \mathrm{C}$. Figure 7 shows the annual average outlet temperature from the storage tank and the outlet desired temperature after passing through the auxiliary heaters.

\subsection{Solar fraction and thermal efficiency}

Figure 8 shows system solar fraction and thermal energy conversion efficiency of solar collector field.

\subsection{Effect of operating conditions}

The effect of hot water temperature on the solar fraction of the system when the working water temperature is raised from 70 to $80{ }^{\circ} \mathrm{C}$ is shown in Figure 9. The annual solar fraction is reduced by $11 \%$ to $68.6 \%$. However, this will not affect the fresh water productivity.

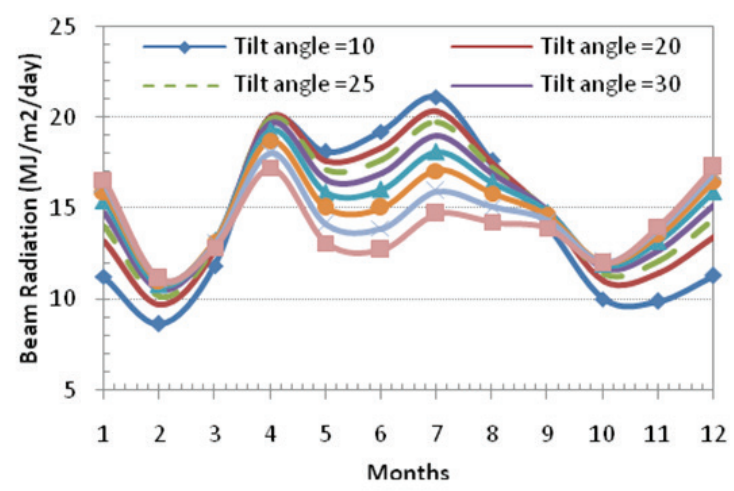

Figure (6). Distribution of monthly beam solar radiation at different tilt angles

The effect of operating hours during the day is also presented in Figure 10. The results showed that increasing operating hours at working water temperature of $70{ }^{\circ} \mathrm{C}$ decreased the contribution of the solar energy in the system, but the amount of 
fresh water produced will be increased.

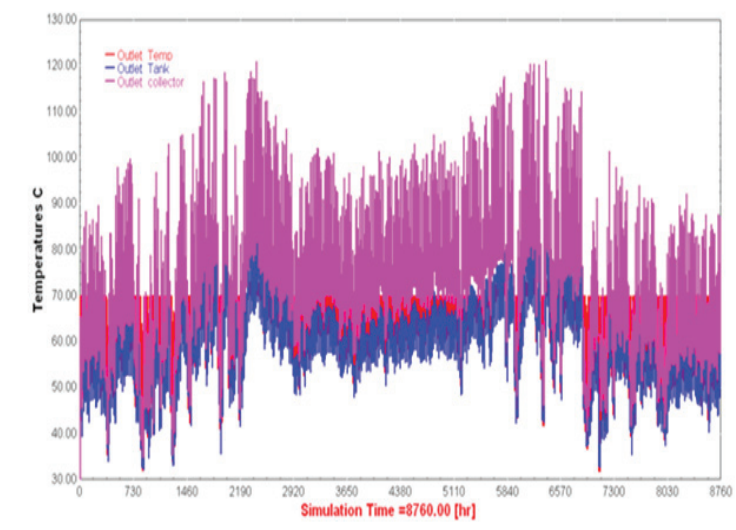

Figure (7). Outlet temperature from the storage tank and the heaters at different collector tilt angles

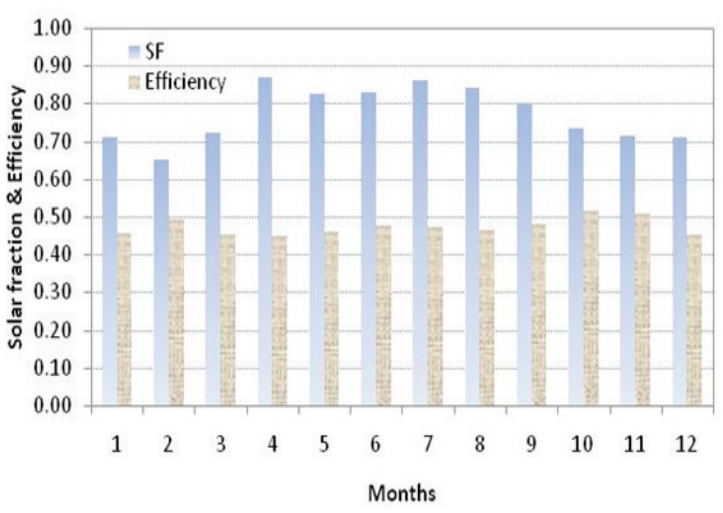

Figure (8). Solar fraction and thermal energy conversion efficiency of the system

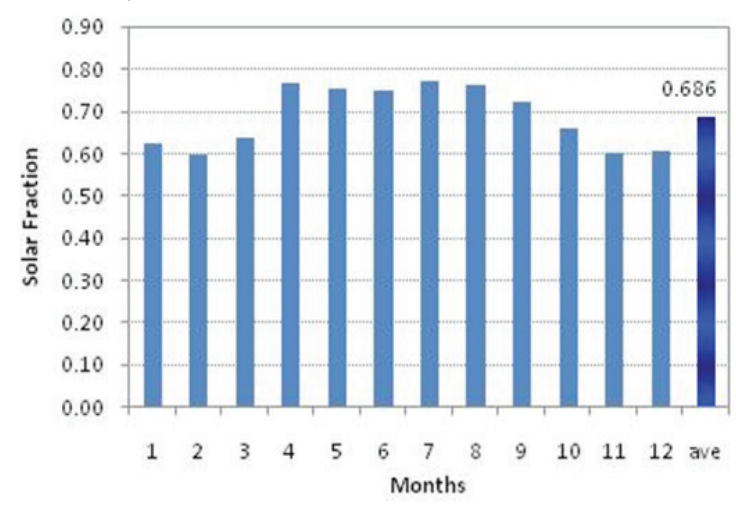

Figure (9). System solar fraction at working water temperature of $80^{\circ} \mathrm{C}$

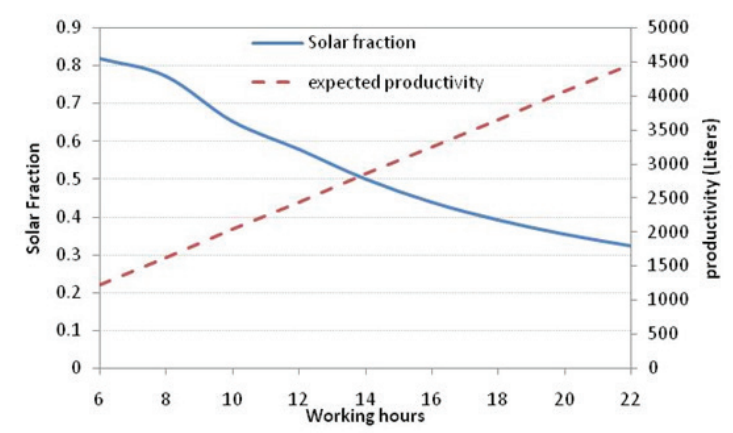

Figure (10). Effect of working hours on the system solar fraction and fresh water productivity

\section{CONCLUSION}

The study attempts to find the best performance configuration of solar thermal collector field to provide thermal energy for the MSF desalination plant. The configuration layout-3 was found better performance than the other configurations considered in this study.

Through the use of simulation, the study has shown that the collector thermal field (layout-3) can provide $77 \%$ of the required thermal energy from solar with an average annual thermal energy conversion efficiency of $47.3 \%$. The operating condition was 8 hours daily at a temperature of $70{ }^{\circ} \mathrm{C}$. The expected fresh water productivity is about 1640 litres of fresh water daily with salinity less than 100 ppm for 8 working hour per day.

Running the desalination plant for 24 hours a day reduces the solar fraction of the solar collector field to $25 \%$ with expected fresh water production of 4640 litres per day.

Finally we can conclude that, the results obtained from simulation were very 
encouraging to install the system and take real measurements for further modeling and validation.

\section{REFERENCES}

[1]. P.V. Kumar et el, "Optimization of design and operating parameters on the year round performance of a multi-stage evacuated solar desalination system using transient mathematical analysis", International Journal of Energy and Environment, Volume 3, Issue 3, pp 409-434, 2012.

[2].S. A. Kershman, 25 years of experience in operating thermal desalination plants, Desalination 136, 2001, 141-145.

[3]. S.A. Kalogirous, Seawater desalination using renewable energy sources, Progress in Energy and Consumption Science, 31, 2005, 242-281

[4].H.T El-Dessouky and H.M.Ettouney," Fundamentals of salt water desalination",
Elsevier Science B.V., 2002.

[5]. T. A. Ghanem and M. Kherallah, "Water in Arab Countries" International Fund for Agricultural Development, IFAD, Via Paolo di Dono, Rome, Italy.

[6]. General Electric Company of Libya, annual report, 2009.

[7]. Agha K.R, Abughres S.M. and Ramadan A.M., "Design Methodology for a Salt Gradient Solar Pond Coupled with an Evaporation Pond", Solar Energy Journal, 72, 447-454, 2002.

[8]. Agha K.R., Abughres S.M. and Ramadan A.M. "Maintenance Strategy for a Salt Gradient Solar Pond Coupled with an Evaporation Pond", Solar Energy Journal, 77, 95-104,2004.

[9]. TRNSYS : a transient simulation program version 17.00.0019, Solar Energy Laboratory: Madison University of Wisconsin, USA. 
ANNEX (A). LAYOUT CONFIGURATION OF THE SUGGESTED SOLAR THERMAL

\section{PLANTS}

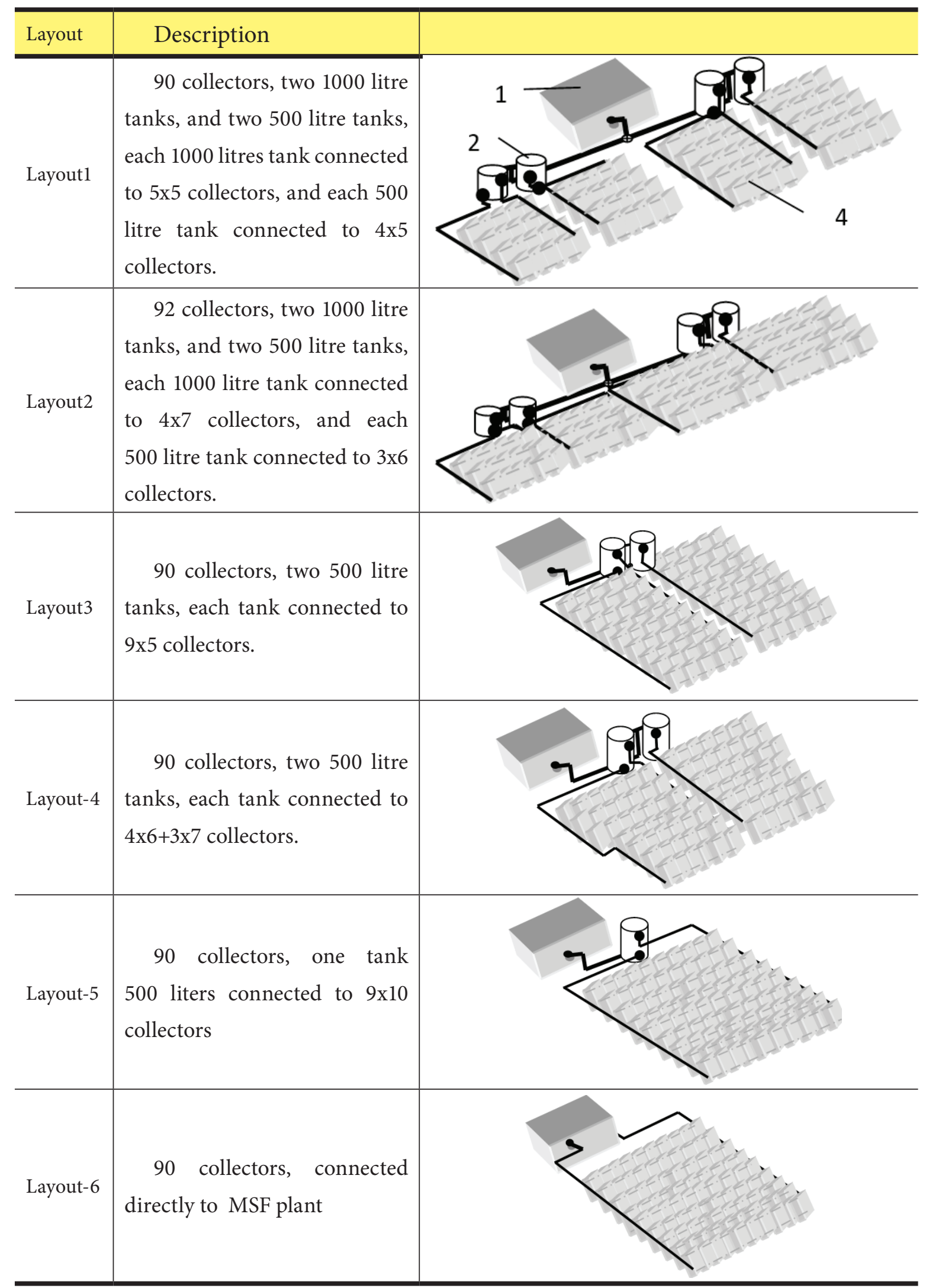

1- MSF desalination unit, 2- Insulated storage tank, 3- Solar collector field 